\title{
IMAGE OF TAIWAN HELD BY MALAYSIAN MUSLIM TOURISTS: MOTIVATIONAL FACTORS INFLUENCING OVERALL IMAGE EVALUATIONS
}

\author{
YIAP LING CHEK \\ Ghazali Shafie Graduate School of Government \\ Universiti Utara Malaysia
}

\begin{abstract}
In the recent years, the Muslim international tourists market has become the focus of the tourism industries in the Asia Pacific. Taiwan has also noticed the potential of this market segment, and started promoting its tourism products to the international Muslim tourists. In order to promote Taiwan effectively to this market segment, it is important to identify the factors that influence the perception of the Muslim tourists about Taiwan. With this notion, this study set out to establish the previsit tourism image of Taiwan held by the Muslim tourists, and determine the factors that influence the Muslim tourists' image evaluations. This study employed both structured and unstructured methods in the survey, and the data was analysed using content analysis, factor analysis, and structural equation modeling. The findings indicated that Muslim tourists generally have a positive image of Taiwan; however, this image is fuzzy. Furthermore, the direct effect of travel motivation on affective images was significant, and the 'Relax' dimension of travel motivation has the greatest impact. However, the 'Religious' dimension of travel motivation did not have significant effect on affective image.
\end{abstract}

Keywords: Destination image, Muslim tourists, Islam, travel motivations.

\section{Introduction}

\section{Research Background}

The world population of Muslims has grown tremendously since Islam was founded in the seventh century. By the end of 2010, the estimated world population of Muslims is about 1.6 billion, or $23 \%$ of world's population, making Islam the world's second-largest religion after Christianity (Pew Research Centre 2012). Muslim countries are considered as the emerging tourism market of the future with huge economic, demographic, and destination potential (Al-Hamarneh \& Steiner, 2004). The Taiwan Tourism Bureau had also noticed the potential of Muslim tourist market, and actively promoted Taiwan as a holiday destination to the Muslims in Southeast Asia region since 2008, particularly Malaysia and Indonesia due to the proximate location and economic viability of these countries. However, this development is still in the infant stage and the International Muslim tourist arrivals in Taiwan have yet to increase significantly.

The Muslims tourists are a distinct group despite being avid travelers due to the religious requirements in terms of food and religious duty which must be adhered in their daily life even while travelling (Scott \& Jafari, 2010; Timothy \& Iverson, 2006). Although Islam encourages travel, it also requires Muslim tourists to pray daily while prohibiting them from engaging in unlawful activities, e.g. gambling, prostitution etc. Thus, capturing this lucrative tourist market would require an understanding of the distinctive travel behavior of the Muslim tourists to allow an effective marketing strategy that is consistent with their culture. 


\section{Theoretical Base}

In order to attract the Muslim tourists to visit, an understanding of the factors influencing the behavior of Muslim tourists in destination selection is essential. It has been generally accepted that tourism destination image (TDI) plays an important role in destination selection process (Ahmed, 1991; Chen \& Tsai, 2007; Dann, 1996; Gartner, 1993; Hunt, 1975). Destination image is regarded as a crucial marketing concept in the tourism industry (Kim \& Richardson, 2003), and in order to encourage a desire to visit, destination marketing organizations (DMO) have to develop a favorable image of their destinations through marketing (Phelps, 1986). Furthermore, Hunt (1975) argued that while a destination may have unique and high quality tourism products, a distorted image could undermine the potential of the destination and hinder successful development. Findings from TDI research, particularly the measurement of TDI can help DMO identify a destination's strengths and weaknesses, as well as providing critical insights on service delivery and product development (Chen, 2001). Moreover, accuracies and inaccuracies of the existing destination image could be effectively addressed in the design of the promotional strategy (Echtner \& Ritchie, 2003). As such, TDI is an important marketing tool that assists the DMO to achieve a desirable positioning of their products, by managing the images that potential tourists hold about the destinations (Stepchenkova \& Morrison, 2008).

Tasci and Gartner (2007) pointed out that image projected by the DMO is not always the same as the image perceived by the tourist, because the original message may be altered or modified by the perceiver/tourist. Beerli and Martin (2004b) argued that perception is the process through which an individual selects, organizes and interprets incoming information to form an image, which may vary from person to person. Baloglu and McCleary (1999) described destination image formation as the mental process that involves the cognitive and affective evaluations that resulted in an overall image of the destination. The authors proposed that these image evaluations are influenced by stimulus factors (e.g. information received) and personal factors (e.g. travel motivations and socio-demographic characteristic); the stimulus factors generate the cognitive image, while the personal factors influence the cognitive and affective evaluations. Moreover, affective image, which has a greater impact in the image formation process as compared with cognitive image, has been found to be influenced by travel motivations directly (Baloglu \& McCleary, 1999; Beerli \& Martin, 2004a; San Martin \& Rodríguez del Bosque, 2008). Therefore, the success of the DMO to project an effective destination image to the targeted market would depend on the ability of the DMO to make informed decisions based on valid assumptions about the influences of travel motivations in destination image formation.

Regarding the impact of travel motivations on destination image formation, many studies have been done in the past to examine various dimensions of travel motivations except the effect of religious dimension (Baloglu \& McCleary, 1999; Beerli \& Martin, 2004a; Crompton, 1979b). Being affluent travelers with a unique cultural background, the Muslim tourists may be influenced by religious factor in the way they perceive a destination. Therefore, they are selected as the research subject of this study to help identify the motivational factors that influence the image formation process. As for the research object, Taiwan stands out as the best candidate due to the richness of its tourism resources, and its potential in attracting the Muslim tourists from the neighboring countries. Moreover, the formation of image perceived by tourists, especially in the absence of actual visitation (secondary image), is the most important phase in tourists' destination selection processes (Baloglu \& McCleary, 1999; Echtner \& Ritchie, 2003; Gunn, 1972). Hence, the questions raised in this study are: One, what is the image of Taiwan perceived by the Muslim tourists with no previous travelling experience in 
Taiwan? Two, what are the information sources that the Muslim tourists would rely most? And three, what are the salient travel motivations (general and religious) that influence their image evaluations? This study seeks to address the issues mentioned above and to achieve the following objectives:

1. To ascertain the perceived images of Taiwan held by the Muslim tourists who have not visited Taiwan before;

2. To identify the type of information sources that the Muslim tourists would rely upon in forming impressions about Taiwan;

3. To identify the motivational factors that would significantly influence the Muslim tourists' evaluations in the image formation process.

\section{Literature Review}

\section{Tourism Destination Image: Definitions and Concepts}

Destination image may be defined as the expression of all knowledge, impressions, prejudices, imaginations and emotional thoughts an individual or group has of a specific place (Baud-Bovy \& Lawson, 1977). Crompton (1979a) defined TDI as the sum of beliefs, ideas, and impressions that a person has of a destination. It is not what tourists know as objective fact, but what they 'think' or 'feel' subjectively about a destination (Ahmed, 1991). Images held of a destination may be either positive or negative, although in reality they usually consist of both positive and negative images (Pike, 2004).

Destination image consists of functional characteristics - concerning the more tangible aspects of the destination, such as scenery, attractions, accommodation facilities and price level; and psychological characteristics - concerning the more intangible aspects, such as friendliness, safety and atmosphere (Echtner \& Ritchie, 2003). There are two important components of image - cognitive, and affective, which are associated with intellectual appraisal and motivational evaluation respectively (Baloglu \& McCleary, 1999; Dann, 1996). The cognitive image is an evaluation of the known attributes of the product or the understanding of the product in an intellectual way (Scott, 1965). In the context of TDI, the known attributes are the characteristics of the destination, such as attractions, economic and social environment, facilities, etc. The affective component of image refers to the emotional response or feeling of an individual towards a place, which may be favorable, neutral or unfavorable (Baloglu \& Brinberg, 1997; Fishbein, 1967). It is related to the motives one has for destination selection (Gartner, 1993). Motives determine what one wish to obtain from the object being considered thus affecting object valuation (Boulding, 1956).

\section{Destination Image Formation}

Quoting Reynolds (1965), Echtner and Ritchie (2003, p. 38) described the formation of image as "the development of a mental construct based upon a few impressions chosen from a flood of information." Based on the review of TDI articles between 1971 and 1999, Gallarza, Saura, and Garci'a (2002) concluded that Gartner (1993) presents useful theoretical insights on image formation process, and the model of destination image formation (Figure 1) proposed by Baloglu and McCleary (1999) provides an excellent, overall and comprehensive concept of destination image formation. Gartner (1993) suggested that the image forming process can be regarded as a continuum of different information sources which act independently to form one single image in the mind of the perceiver. Moreover, Gunn (1972) argued that the initial image formation stage before the trip is the most important phase in tourists' destination selection processes because a tourist's image of a destination is generally very resistant to change once it is formed. Baloglu and McCleary's (1999) study provides valuable insights into the development of this mental construct or image held prior to visit. 


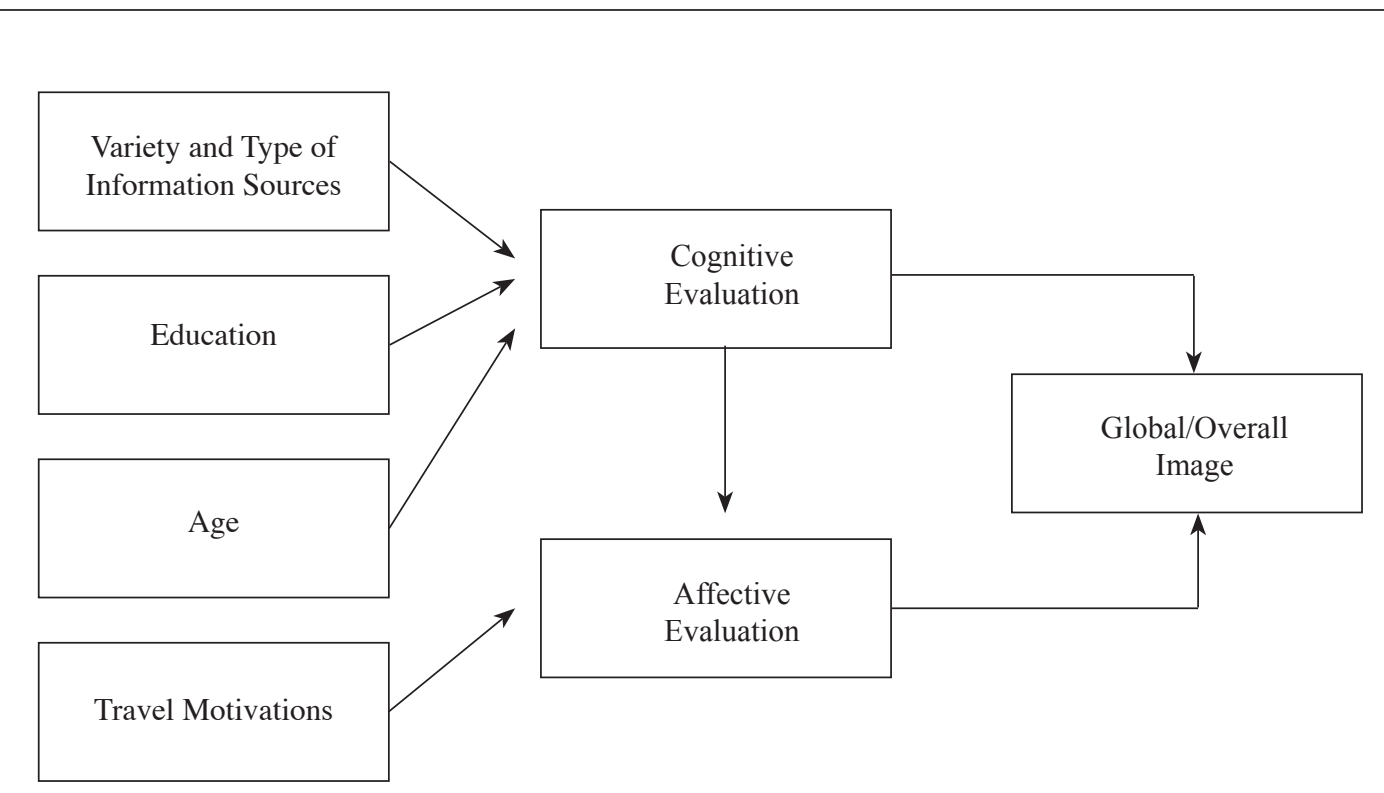

Source. Adapted from Baloglu and McCleary (1999)

Figure 1. A Model of destination image formation

The concept of this model (Figure 1) suggests that there are different levels of evaluations within the image formation (cognitive, affective, and global/overall image). The cognitive evaluations are the beliefs of the tourist about a destination's attributes, whereas affective evaluations refer to the tourist's feelings toward the destination. These evaluations would act together to produce the global image which is the tourist's overall impression of a place (Baloglu \& McCleary, 1999). The concept also suggests that cognitive and affective evaluations are influenced by both the external factors which include various information sources consisting of symbolic stimuli (e.g. advertisement) and social stimuli (e.g. word-of-mouth), and personal factors which include travel motivations and demographic variables (Baloglu \& McCleary, 1999). With this concept, Baloglu and McCleary (1999) conducted an empirical study to investigate the relationships within this model. Results from their study revealed that information sources, age, and education indirectly influence affective evaluations through cognitive evaluations, whereas direct effects come from travel motivations and cognitive evaluation. Both cognitive and affective evaluations directly influence overall image. However, the effect from affective evaluations is much greater than cognitive evaluations.

\section{Factors Influencing Destination Image Formation}

Baloglu and McCleary's model provides a foundation for future studies of TDI, and many TDI studies that were undertaken after this model was proposed, have adopted the multidimensional concept of image construct (cognitive, affective, and global/overall image) in their studies (e.g. Baloglu, 2001; Beerli \& Martin, 2004a; Kim \& Richardson, 2003; Qu, Kim, \& Im, 2011; San Martin \& Rodríguez del Bosque, 2008). The model suggests that in 
the absent of actual visit, information sources, travel motivations, and socio-demographic characteristics are the major factors that influence the image evaluations. However, in relation to the objectives of this study, focus will be given to two factors - 'Information sources' and 'Travel Motivations'.

(a) Information Sources - refers to "the amount and diverse nature of information sources to which individuals are exposed, including destination information acquired as a result of having visited the place" (Beerli \& Martin, 2004a, p. 661). Information sources play an important role in destination image formation as they are the primary ingredients in the image formation process that give the tourist the knowledge concerning a destination before the evaluation process begins. Gartner (1993) identified eight types of information sources, namely Overt Induced I - consist of traditional forms of advertising, such as the use of television, radio, and print media advertising by DMO; Overt Induced II - consist of information received or requested from tour operators, and organizations which have a vested interest in the travel decision process but which are not directly associated with a particular destination area; Covert Induced I - the use of a recognizable spokesperson or celebrity in traditional forms of advertising; Covert Induced II - consist of articles, reports, or stories about a particular place, from an unbiased source; Autonomous - consist of independently produced reports, documentaries, movies, and news articles about the destination; Unsolicited Organic - refers to unrequested information received from individuals who have been to an area, or believe they know what exists there; Solicited Organic - include requests from knowledgeable sources (e.g. friends and relatives), about what exists at the destination; and Organic - consist of information acquired about a destination based on previous travel to the area. (b) Travel Motivations - The term 'motivation' has at least two accepted meanings: it refers to the organismic energy or drive that makes action possible; and it is also conceived as the innate tendencies to orient and act in a certain fashion (that is, to see certain things, to want certain things, and to do certain things) as to acquire certain goal objects (Parsons \& Shils, 2001). Iso-Ahola (1982) proposed a social psychological theory of tourism motivation which states that tourism behavior is influenced by two motivation forces: escaping - the desire to leave the everyday environment behind oneself, and seeking - the desire to obtain psychological rewards (e.g. learning about other culture, interacting with others, ego-enhancement and prestige) through travel in a contrasting environment. The tourism literature has long recognized that a pleasure trip is rarely the result of a single motive (Crompton \& Stacey, 1997). When individuals decide to travel for pleasure, they do so for various reasons, and their motives could be multiple. Crompton (1979b) conceptualized tourism motivations into seven dimensions: Novelty - a desire to seek out new and different experience; Socialization - a desire to interact with a group and its members; Prestige - a desire to have high standing in the eyes of others; Rest \& Relaxation - a desire to refresh oneself mentally and physically; Intellectual Enrichment - a desire to gain knowledge and expand intellectual horizons; Family Togetherness - a desire to enhance family relationship; and Regression - a desire to engage in behavior reminiscent of an adolescent or child. While these factors represent the travel motivations that are generally found in most tourists, this study took one step further to examine the travel motivations of Muslim tourists with a new dimension - the religious motivations. 


\section{Islam and Tourism}

Islam literally means "submission to Allah (God)" calls for the believers to submit to God in every aspect of their lives, including leisure. Din $(1989$, p. 552$)$ argued that travel in Islam may be described as "purposeful tourism which differs from the common practice of mass tourism which is motivated mainly by pleasure and hedonistic pursuits." The author elaborated the Islamic concept of tourism as follows:

"Muslims as hosts and guests are repeatedly enjoined to support $F i$ Sabilillah (in the cause of God), and one of the approaches to this goal is through travel. Muslims are encouraged to travel though the earth so that they can appreciate the greatness of God through observing the "signs" of beauty and bounty of His creations...the spiritual goal is to reinforce one's submission to the ways of God, the social goal which follows is to encourage and strengthen the bond of sillaturahim (Muslim fraternity) among the Ummah (Muslim community)" (pp. 551-552).

Thus, when the Muslims travel for leisure purposes, it can enhance their spirituality through observing and appreciating nature, and strengthen the bond between the Muslim communities through socializing with believers in foreign places. Therefore, these religious motives such as 'submission to God', 'contemplating the creation of God', and 'strengthening bond with other Muslim communities' could be the factors that form the Muslims' travel motivations.

From the aforementioned discussions, this study concluded that destination image formation is a psychological phenomenon in which an individual processes the information regarding a destination acquired from various sources to form a mental image. This mental process involves cognitive and affective evaluations, and the joint effect of these two evaluations produces an overall image. Although the affective image appears to have a greater effect on overall image as compared to the cognitive image, the role of cognitive image should not be ignored since it is the input for affective image. Factors such as information sources, travel motivations, and socio-demographic characteristics also have an impact on destination image formation. While past studies have revealed that travel motivations exert a direct impact on the affective image, effect of the religious dimension is still uncertain. Considering the unique cultural background of the Muslim tourists, one would wonder whether this factor would have any effect on the way they perceive a destination. Thus, two research hypotheses had been proposed for this study: Hypothesis 1-The religious motivations of the Muslims significantly influence their cognitive evaluations; and Hypothesis 2-The religious motivations of the Muslims significantly influence their affective evaluations.

\section{Methodology}

This study employed the explanatory research design for the testing of hypotheses to confirm causal relationships between travel motivations (general and religious) and other constructs in image formation. Data was collected by a selfadministered questionnaire using both structured and unstructured methods to measure the image of Taiwan and other constructs. This would produce a more complete and comprehensive measurement of destination image, as well as produce valid results (Echtner \& Ritchie, 2003; Jenkins, 1999).

Survey was carried out at the Kuala Lumpur International Airport (KLIA) to meet the potential Muslim tourists. Prior to that, the questionnaire was reviewed by a penal of three experts, and then revised according to their inputs to achieve face validity (Vaske, 2008). The revised questionnaire was pilot-tested on a sample 100 Muslim travelers at KLIA to identify area of weakness and also to improve its reliability and validity (Neuman, 2000). Subsequently, on-site survey was conducted from February 14, 2012 to February 27, 2012. A 
sample size of 400 was targeted. This sample size is considered to be suitable for generalization for most human dimensions studies (Vaske, 2008). As for the sampling method, this study has to take into consideration the constraints of time, cost, and the social context of the population. The Islamic societies are generally conservative and the people are very reluctant to participate in the survey (Alghamdi, 2007). Therefore, convenience sampling method was adopted in this study for practical reason. However, only one sample was collected from members of the same group to increase the representativeness of the sample. The respondents were asked to complete the questionnaire which has been ordered according to following sequences:

(a) Screening - This section screens the respondents using two close-ended questions (Yes or No). Respondents were asked to confirm their religion, and whether they had previously visited Taiwan. Only those who stated that they are Muslim and have not visited Taiwan would constitute a valid sample.

(b) The perceived image of Taiwan Respondents were asked to describe their impression of Taiwan in two open-ended questions. The first question requires the respondents to describe any positive impression they have about Taiwan using three (3) words/phrases. The second question requires the respondents to describe any negative impression they have about Taiwan using three (3) words/ phrases.

(c) Information sources - Nine items, namely 'Tour operators/travel agent', 'Airlines', 'Friends or relative', 'Internet travel blogs', 'Advertisements in massmedia', 'News, reports or documentary', 'Movie/drama series', 'Travel fair', and 'Books/magazines' were generated based on past studies (e.g. Baloglu \& McCleary, 1999; Beerli \& Martin, 2004a; Bieger \& Laesser, 2004). Respondents were asked to indicate the level of importance of each information sources that would influence their perception of Taiwan on a 5-point
Likert scale, ranging from "not important at all" to "very important".

(d) Travel motivations - 28 motivation items consisting 25 general motivation items and 3 religious motivation items were generated from literature review (e.g. Alghamdi, 2007; Baloglu \& McCleary, 1999; Beerli \& Martin, 2004a; Din, 1989; Yoon \& Uysal, 2005; Young, 1999). Respondents were asked to evaluate each reason for travel on a 5-point Likert-type scale ranging from "Not important at all" to "Very important".

(e) Cognitive images - 24 items were generated from literature review (e.g. Baloglu \& McCleary, 1999; Beerli \& Martin, 2004a; Chen \& Tsai, 2007; Lin, Morais, Kerstetter, \& Hou, 2007), content analysis of Taiwan's official tourism website and guidebook, as well as various sources of this study. Respondents were asked to rate each item based on their perception of Taiwan as a vacation destination on the scale of 1 (Strongly Disagree) to 5 (Strongly Agree). A 'No opinion' column was added next to the scale as an option for those respondents who have no true opinions.

(f) Affective images - This study adopted the four bipolar scales (Unpleasant-Pleasant, Boring-Exciting, Sleepy-Arousing, and Distressing-Relaxing) used by Baloglu and McCleary (1999). Respondents were asked to indicate their feelings toward Taiwan as a vacation destination on the bipolar scales which rate from one to five.

(g) Overall image - Respondents were asked to indicate their overall impression of Taiwan on a 5-point anchor scale ranging from "very negative" to "very positive" (Baloglu \& McCleary, 1999; Beerli \& Martin, 2004a).

(h) Socio-demographic information - The last section of the questionnaire would collect socio-demographic information such as age, gender, marital status, level of education, income, and occupation of the respondents for descriptive analysis and reporting. 


\section{Results}

A total of 772 travelers were approached at the KLIA during the on-site survey, of which $322(42 \%)$ refused to participate yielding 450 responses which gives a response rate of $58 \%$, which is considered acceptable by most researchers (Neuman, 2000). Out of these samples, only 409 constitute usable samples. The invalid responses constituted almost $10 \%$ of the total sample collected. Nevertheless, the usable sample size still met the requirements to generalize the targeted population and statistical analysis techniques used in this study. Data were analysed using statistical analysis software SPSS version 17 and Amos version 18. Structural Equation Modeling (SEM) was used to examine the relationships in the image formation, and for the testing of the hypothesis. Prior to SEM, Exploratory Factor Analysis (EFA) was used to identify the dimensions associated with the cognitive image and travel motivations.

The demographic profile of the respondents indicated that the samples are equally distributed between both sex, with $50.1 \%$ male and $49.9 \%$ female. Majority of them (61.1\%) have an annual income of MYR45,000 and above. The respondents are mostly highly educated (92.2\%) comprising professionals, business executives/ managers, legislator/government officers and students. In term of age, most of them are within 20-59 year old (95.6\%) and can be considered as independent and mobile persons. Overall, the samples represent potential Muslim tourists and meet the objectives of this study.

The image of Taiwan were assessed through two methods - structured and unstructured. Content analysis was done to analyse data collected from unstructured method, whereas frequency analysis was used to analyse data from structured method. Results from the unstructured query showed that $79 \%$ of the respondents had a positive image of Taiwan. The number of positive comments (721) outweigh the negative comments (299) by more than double. However, less than half of the respondents were able to provide three or more comments, while some $(18.3 \%)$ could not give any comment, indicating that even though most of the respondents had some knowledge about Taiwan, only few had strong impression of the country. Concerning the positive images held by the respondents, 'beautiful island/country' (31.5\%) was on top of the list, whereas concerning negative image of Taiwan, 'Lack of halal food' (25.2\%) was mentioned most. A few wrong comments were also found, such as 'Disneyland', 'French influence', and 'Communist'.

In the structured method, the cognitive, affective, and overall images of Taiwan were measured. The results (Table 1) showed that the overall image of Taiwan was positive $(M=3.84)$. When asked to rate the 24 touristic attributes of Taiwan, almost all of the attributes received a mean of 3.50 and above except one item, 'Appealing halal cuisine/food' $(M=3.43)$. Moreover, 15 attributes have 'No opinion' responses as high as $30 \%$ or more. This mean Taiwan is not widely known as a tourist destination among the respondents. Moreover, the respondents rated most of the Islamic attributes e.g. 'Friendly environment for Muslims', 'Interesting Islamic culture', and 'Appealing halal cuisine/foods' lower than the rest of the attributes. All four indicators of affective image received a mean of 3.50 and above, indicating the respondents generally have a positive feeling towards Taiwan.

The second research objective of this study is to identify the type of information sources that the Muslim tourists would rely upon in forming impressions about a destination. The results showed that when considering Taiwan as a tourist destination, the respondents would rely on 'Advertisements in mass-media' $(M=4.19)$ and 'Internet travel blogs' $(M=4.18)$ the most, followed by 'News, reports or documentary' $(M$ =4.10), 'Travel fair' $(M=4.05)$, 'Tour operators or travel agent' $(M=3.93)$, 'Friends or relatives' $(M=3.90)$, 'Books or magazines' $(M=3.89)$, 'Airlines' $(M=3.75)$, and least likely to rely on 'Movies/drama series' $(M=3.45)$. 
Table 1

Image of Taiwan Based on Structured Query

\begin{tabular}{|c|c|c|c|}
\hline Image descriptor & $\begin{array}{c}\text { Mean } \\
(M)\end{array}$ & $\begin{array}{c}\text { No opinion } \\
(n)\end{array}$ & $\%^{\mathrm{a}}$ \\
\hline \multicolumn{4}{|c|}{ Cognitive image ${ }^{\mathrm{b}}$} \\
\hline Beautiful sceneries and natural landscape & 4.13 & 52 & 12.7 \\
\hline Good telecommunication & 4.13 & 119 & 29.1 \\
\hline Various shopping opportunities & 4.08 & 99 & 24.2 \\
\hline Good transportations & 4.01 & 118 & 28.9 \\
\hline Interesting cultural attractions & 3.98 & 93 & 22.7 \\
\hline Nice weather & 3.92 & 96 & 23.5 \\
\hline Interesting amusement and theme parks & 3.90 & 149 & 36.4 \\
\hline Nice islands and beaches & 3.90 & 156 & 38.1 \\
\hline Safe place to travel & 3.89 & 108 & 26.4 \\
\hline Interesting hot springs and spa & 3.87 & 187 & 45.7 \\
\hline Interesting festivals and concerts & 3.87 & 138 & 33.7 \\
\hline Interesting museums and historical attractions & 3.86 & 141 & 34.5 \\
\hline Suitable accommodations & 3.86 & 126 & 30.8 \\
\hline Great variety of fauna and flora & 3.85 & 110 & 26.9 \\
\hline Hospitable and friendly people & 3.83 & 147 & 35.9 \\
\hline Good destination for family & 3.80 & 77 & 18.8 \\
\hline Standard hygiene and cleanliness & 3.79 & 139 & 34.0 \\
\hline Unique mosques & 3.78 & 203 & 49.6 \\
\hline Interesting leisure farms & 3.75 & 188 & 46.0 \\
\hline Good value for money & 3.72 & 146 & 35.7 \\
\hline Nice hiking and biking trails & 3.72 & 187 & 45.7 \\
\hline Friendly environment for Muslims & 3.63 & 145 & 35.5 \\
\hline Interesting Islamic culture & 3.54 & 177 & 43.3 \\
\hline Appealing halal cuisine/foods & 3.43 & 147 & 35.9 \\
\hline \multicolumn{4}{|c|}{ Affective image $^{c}$} \\
\hline Pleasant & 3.81 & & \\
\hline Exciting & 3.79 & & \\
\hline Relaxing & 3.77 & & \\
\hline Arousing & 3.67 & & \\
\hline Overall image $^{\mathrm{d}}$ & 3.84 & & \\
\hline
\end{tabular}

${ }^{\text {a }}$ Percentile based on total number of samples $(N=409)$

b Based on a 5-point scale from 1 = "strongly disagree" to 5 = "strongly agree".

${ }^{c}$ Based on a 5-point bipolar scale

"Based on a 5-point scale from $1=$ "very negative" to 5 = "very positive". 
Table 2

Factor Analysis and Reliability Test of Travel Motivations

\begin{tabular}{|c|c|c|c|c|c|c|c|c|c|}
\hline \multirow[b]{2}{*}{ Variable } & \multicolumn{6}{|c|}{ Component } & \multirow{2}{*}{$\begin{array}{l}\text { Variance } \\
\text { explained }\end{array}$} & \multirow{2}{*}{$\begin{array}{l}\text { Item-total } \\
\text { correlation }\end{array}$} & \multirow{2}{*}{$\begin{array}{l}\alpha \text { if item } \\
\text { deleted }\end{array}$} \\
\hline & 1 & 2 & 3 & 4 & 5 & 6 & & & \\
\hline \multicolumn{7}{|c|}{ Prestige (MOT 1) (.74) ${ }^{\mathrm{a}}$} & $12.80 \%$ & & \\
\hline $\begin{array}{l}\text { Places friend want } \\
\text { to go }\end{array}$ & .84 & .12 & .05 & .12 & .03 & -.02 & & .64 & .61 \\
\hline Place friend not been & .72 & -.13 & .04 & .03 & .05 & .27 & & .50 & .71 \\
\hline Time with friends & .72 & .25 & .06 & .20 & .07 & .04 & & .56 & .66 \\
\hline Meet new people & .50 & .08 & .25 & .17 & .36 & .17 & & .45 & .72 \\
\hline
\end{tabular}

Family Togetherness (MOT 2) (.81) a

$12.78 \%$

$\begin{array}{lllllllll}\text { Together as family } & .03 & .82 & .08 & .17 & .14 & .17 & .71 & .70\end{array}$

$\begin{array}{lllllllll}\text { Closer as family } & .10 & .81 & .06 & .05 & .22 & .16 & .66 & .75\end{array}$

\begin{tabular}{lllllllll} 
Time with family & .12 & .78 & .17 & .26 & -.04 & .03 & .62 & .78 \\
\hline
\end{tabular}

Novelty (MOT 3) (.68) a $11.38 \%$

$\begin{array}{llllllllll}\text { Curiosity } & .04 & .04 & .80 & .14 & -.05 & .14 & .50\end{array}$

$\begin{array}{lllllllll}\text { Seeing new place } & .08 & .14 & .75 & .26 & .10 & .05 & .54\end{array}$

$\begin{array}{llllllllll}\text { Different culture } & .14 & .16 & .62 & -.04 & .45 & -.10 & .06\end{array}$

Relax (MOT 4) (.76) a $11.08 \%$

\begin{tabular}{lllllllll} 
Relieving stress & .16 & .26 & .18 & .78 & .03 & .02 & .64 & .60 \\
Relax & .24 & .16 & .17 & .77 & .13 & .02 & .68 & .56 \\
Learn new thing & .09 & .08 & .48 & .52 & .18 & .17 & .46 & .80 \\
\hline
\end{tabular}

Love Nature (MOT 5) (.65) a

$10.66 \%$

$\begin{array}{lllllllll}\text { Close to nature } & .06 & .11 & .03 & .32 & .77 & .17 & .63 & \end{array}$

$\begin{array}{lllllllll}\text { Rural countryside } & .29 & .11 & .22 & -.16 & .70 & .02 & .35 & .70\end{array}$

\begin{tabular}{lllllllll} 
Appreciate God & -.19 & .16 & -.06 & .36 & .57 & .38 & .43 & .60 \\
\hline
\end{tabular}

$\begin{array}{ll}\text { Religious (MOT 6) (.82) }{ }^{\text {a }} & 10.39 \%\end{array}$

$\begin{array}{llllllll}\text { Bond with Muslim } & .17 & .12 & .11 & .04 & .11 & .86 & .70\end{array}$

$\begin{array}{llllllll}\text { Visit mosque } & .14 & .19 & .07 & .05 & .12 & .86 & .70\end{array}$

Total Variance Explained

$69.10 \%$

Kaiser-Meyer-Olkin Measure of Sampling Adequacy

Bartlett's Test of Sphericity:

Approx. Chi-Square

Sig.

.00

a Reliability score (Cronbach's alpha) for each factor grouping is shown in parentheses. 
Table 3

Factor Analysis and Reliability Test of Cognitive Images

\begin{tabular}{|c|c|c|c|c|c|c|c|}
\hline \multirow[b]{2}{*}{ Variable } & \multicolumn{4}{|c|}{ Component } & \multirow{2}{*}{$\begin{array}{l}\text { Variance } \\
\text { explained }\end{array}$} & \multirow{2}{*}{$\begin{array}{l}\text { Item-total } \\
\text { correlation }\end{array}$} & \multirow{2}{*}{$\begin{array}{l}\alpha \text { if item } \\
\text { deleted }\end{array}$} \\
\hline & 1 & 2 & 3 & 4 & & & \\
\hline \multicolumn{5}{|c|}{ Tourist Attractions (COG 1) (.86) ${ }^{\mathrm{a}}$} & $20.56 \%$ & & \\
\hline Hot springs & .72 & .14 & .06 & .28 & & .67 & .84 \\
\hline Museum and history & .70 & .20 & .22 & .00 & & .62 & .84 \\
\hline Festivals & .67 & .26 & -.04 & .24 & & .61 & .84 \\
\hline Hiking and biking & .63 & .03 & .41 & .11 & & .61 & .84 \\
\hline Cultural & .62 & .30 & .01 & .31 & & .62 & .84 \\
\hline Island and beach & .62 & .11 & .37 & -.02 & & .55 & .85 \\
\hline Fauna and flora & .60 & .20 & .32 & .06 & & .59 & .84 \\
\hline Amusement parks & .56 & .23 & .05 & .48 & & .61 & .84 \\
\hline \multicolumn{5}{|c|}{ Islamic Attractions (COG 2) (.85) a } & $16.91 \%$ & & \\
\hline Friendly for Muslim & .16 & .83 & .19 & .12 & & .77 & .79 \\
\hline Halal cuisine & .05 & .82 & .07 & .09 & & .64 & .83 \\
\hline Islamic culture & .30 & .78 & .16 & -.04 & & .74 & .80 \\
\hline Mosques & .29 & .66 & .24 & -.05 & & .61 & .83 \\
\hline Family destination & .32 & .54 & .26 & .24 & & .56 & .85 \\
\hline \multicolumn{5}{|c|}{ Environment (COG 3) (.78) ${ }^{\mathrm{a}}$} & $12.91 \%$ & & \\
\hline Safe place & .17 & .22 & .78 & .16 & & .67 & .67 \\
\hline Hygiene & .08 & .23 & .65 & .46 & & .61 & .70 \\
\hline Accommodation & .15 & .24 & .61 & .36 & & .59 & .72 \\
\hline Weather & .44 & .18 & .57 & -.08 & & .46 & .78 \\
\hline \multicolumn{5}{|c|}{ Infrastructure (COG 4) (.74) ${ }^{a}$} & $11.55 \%$ & & \\
\hline Transportation & .20 & .06 & .22 & .81 & & .59 & \\
\hline Telecommunication & .13 & -.02 & .14 & .78 & & .59 & \\
\hline \multicolumn{5}{|c|}{ Total Variance Explained } & $61.93 \%$ & & \\
\hline \multicolumn{5}{|c|}{ Kaiser-Meyer-Olkin Measure of Sampling Adequacy } & .91 & & \\
\hline \multicolumn{8}{|c|}{ Bartlett's Test of Sphericity: } \\
\hline \multicolumn{4}{|c|}{ Approx. Chi-Square } & \multicolumn{3}{|c|}{1320.77} & \\
\hline \multicolumn{5}{|l|}{ Sig. } & .00 & & \\
\hline
\end{tabular}

a Reliability score (Cronbach's alpha) for each factor grouping is shown in parentheses. 
The third research objective is to identify the motivational factors that would significantly influence the Muslim tourists' image evaluations. $H 1$ and $H 2$ of this study aim to achieve this objective. Before checking the hypotheses, EFA was employed using principal components method with varimax rotation on variables relating to travel motivations and cognitive image in order to extract their respective factors. At the same time, scale reliability of all the factors was tested by means of Cronbach's alpha coefficient to check the internal consistency of the variables. The results are presented in Table 2 and 3 respectively.

Exploratory factor analysis for travel motivations items extracted six factors. All the factors have achieved Cronbach's alpha of above .60; however, MOT 1, MOT 3, MOT 4 and MOT 5 contain items that display unsatisfactory itemtotal correlation. These items are 'Meeting new people' of MOT 1, 'Different culture' of MOT 3, 'Learn new thing' of MOT 4, 'Rural countryside' and 'Appreciate God' of MOT 5, and were assigned for deletion. As a consequence, MOT 5 was left with only one item and would be dropped for further analysis. On the other hand, EFA for cognitive images items extracted four factors. All the factors have obtained Cronbach's alpha exceeding .70 which indicate strong internal consistency. Only one item, 'Weather' of COG 3, has low item-total correlation (.46) and was removed from the scale.

\section{Measurement Model}

The extracted factors were subsequently tested for convergent validity, discriminant validity, and the goodness of the proposed measurement model fits the data set. These tests were carried out using confirmatory factor analysis (CFA), and maximum likelihood estimation (MLE) technique was employed. The model fit indices suggest good fit $\left(x^{2} / d f=1.685\right.$, RMSEA $=$ $.041, \mathrm{SRMR}=.052$, and $\mathrm{CFI}=.892)$. All the constructs have met the criteria of convergent validity except for COG 1 , MOT 1 and MOT 3 . The average variance extracted (AVE) for COG $1(\mathrm{AVE}=.44)$ and MOT $1(\mathrm{AVE}=.49)$ are below the .50 cutoff point. However, the factor loadings and construct reliability of these two construct have all met the standards (Standardized loading estimates value $\geq 0.5$; CR value $\geq 0.7$ ), thus indicate that all the measures consistently represent the latent constructs. As such, the convergent validity of these two constructs can be considered acceptable. As for MOT 3, only the construct reliability (.68) is slightly below the standard. According to Hair et al. (2006), reliability between .6 and .7 can be considered acceptable provided that the other two indicators of construct validity are good. In this case, the factor loadings and AVE of MOT 3 have all met the standards. Overall, the convergent validity of the measurement model of this study can be considered acceptable. The discriminant validity test shows that the AVE estimates of all the constructs are higher than the squared correlation estimates, thus demonstrate their ability to differ from other constructs in the measurement model. Despite a few shortcomings in the construct validity, the measurement model of this study can be considered good as a whole, and the measured variables do logically and systematically represent the respective latent constructs.

\section{Structural Model}

Structural Equation Modeling technique was employed to test the hypothesis of this study and determine the causal relationships between the construct. The validity of the structural model was assessed by overall model fit, and compare it with the CFA fit. The structural model of this study has an adequate fit $\left(x^{2} / d f=1.692\right.$, RMSEA $=.041, \mathrm{SRMR}=.056$, and CFI $=.882$ ) and do not differ substantially from the CFA model fit. The results of causal relationships between the constructs are shown in Table 4. 
Table 4

Standardized Regression Weights of Path Analysis

\begin{tabular}{|c|c|c|c|c|c|c|}
\hline $\begin{array}{c}\text { Endogenous } \\
\text { construct }\end{array}$ & & $\begin{array}{c}\text { Exogenous } \\
\text { construct }\end{array}$ & Estimate & S.E. & $t$-value & $R^{2}$ \\
\hline \multicolumn{7}{|c|}{ Effect of Motivations on Affective Image } \\
\hline AFF & $\leftarrow$ & MOT 1 & $0.43 * * *$ & 0.06 & 4.83 & .39 \\
\hline AFF & $\leftarrow$ & MOT 2 & $0.30 * *$ & 0.09 & 2.93 & \\
\hline AFF & $\leftarrow$ & MOT 3 & $0.32 * *$ & 0.12 & 3.26 & \\
\hline AFF & $\leftarrow$ & MOT 4 & $0.46 * * *$ & 0.11 & 3.30 & \\
\hline AFF & $\leftarrow$ & MOT 6 & 0.13 & 0.06 & 1.75 & \\
\hline \multicolumn{7}{|c|}{ Effect of Motivations on Cognitive Images } \\
\hline COG 1 & $\leftarrow$ & MOT 1 & $0.43 * * *$ & 0.05 & 4.55 & .67 \\
\hline COG 1 & $\leftarrow$ & MOT 2 & $0.40 * * *$ & 0.07 & 3.47 & \\
\hline COG 1 & $\leftarrow$ & MOT 3 & $0.43 * * *$ & 0.10 & 4.00 & \\
\hline COG 1 & $\leftarrow$ & MOT 4 & $0.78 * * *$ & 0.10 & 4.49 & \\
\hline COG 1 & $\leftarrow$ & MOT 6 & $0.29 * * *$ & 0.05 & 3.73 & \\
\hline COG 2 & $\leftarrow$ & MOT 1 & $0.54 * * *$ & 0.07 & 5.73 & .55 \\
\hline $\mathrm{COG} 2$ & $\leftarrow$ & MOT 2 & $0.39 * * *$ & 0.10 & 3.56 & \\
\hline $\mathrm{COG} 2$ & $\leftarrow$ & MOT 3 & $0.23 *$ & 0.14 & 2.41 & \\
\hline $\mathrm{COG} 2$ & $\leftarrow$ & MOT 4 & $0.50 * *$ & 0.14 & 3.28 & \\
\hline COG 2 & $\leftarrow$ & MOT 6 & $0.36 * * *$ & 0.08 & 4.70 & \\
\hline COG 3 & $\leftarrow$ & MOT 1 & $0.48 * * *$ & 0.06 & 4.71 & .70 \\
\hline COG 3 & $\leftarrow$ & MOT 2 & $0.53 * * *$ & 0.09 & 4.15 & \\
\hline COG 3 & $\leftarrow$ & MOT 3 & $0.45 * * *$ & 0.12 & 3.93 & \\
\hline $\mathrm{COG} 3$ & $\leftarrow$ & MOT 4 & $0.59 * * *$ & 0.12 & 3.32 & \\
\hline $\mathrm{COG} 3$ & $\leftarrow$ & MOT 6 & $0.26 * *$ & 0.06 & 3.13 & \\
\hline $\mathrm{COG} 4$ & $\leftarrow$ & MOT 1 & $0.29 * *$ & 0.04 & 3.22 & .41 \\
\hline $\mathrm{COG} 4$ & $\leftarrow$ & MOT 2 & $0.48 * * *$ & 0.07 & 4.08 & \\
\hline $\mathrm{COG} 4$ & $\leftarrow$ & MOT 3 & $0.37 * * *$ & 0.09 & 3.51 & \\
\hline $\mathrm{COG} 4$ & $\leftarrow$ & MOT 4 & $0.49 * *$ & 0.09 & 3.21 & \\
\hline COG 4 & $\leftarrow$ & MOT 6 & 0.05 & 0.05 & 0.72 & \\
\hline
\end{tabular}

$* p<.05 . * * p<.01 . * * * p<.001$. 
The results reveal that all the motivation factors have significant positive effect on every cognitive image factor except the relationship between MOT 6 and COG 4, thus hypothesis one (H1: The religious motivations of the Muslims significantly influence their cognitive evaluations) was strongly supported. However, the effect of religious factor (MOT 6) was not as strong as the rest of the motivation factors. As for hypothesis two $(H 2$ : The religious motivations of the Muslims significantly influence their affective evaluations), the results show that all motivation factors except MOT 6 were found to have significant effect on affective image, thus failed to support $H 2$.

\section{Discussion}

The findings of this study suggested that most respondents had a positive image of Taiwan. However, the negative aspects of the image (e.g. lack halal foods) may hinder them from visiting. Moreover, many respondents do not have good knowledge about Taiwan as a tourist destination. As such, the DMO of Taiwan should increase their effort to promote Taiwan to the Malaysian Muslim markets, and the most effective way is through internet travel blogs, and advertisements in the mass media. Besides introducing the tourist attractions, the availability of halal foods should be emphasized in the marketing programs.

Concerning survey technique, this study has demonstrated that using both structured and unstructured method in measuring TDI would produce a more comprehensive image of a destination. Although this practice has been adopted in past studies, this study took one step further to measure the negative image in a more specific manner through the unstructured enquiry. In this way, both positive and negative images of a destination could be assessed to provide a more objective measurement of TDI. Interestingly, the unstructured enquiry of this study also able to capture some wrong images of the destination, e.g. Taiwan was perceived as a communist country. Moreover, the 'No opinion' option added in the structured enquiry had provided this study the ability to assess the respondents' level of knowledge about the touristic attributes of Taiwan. In this case, it was found that at least $30 \%$ of the respondents unable to rate more than half of the touristic attributes of Taiwan, indicating Taiwan is not widely known to the respondents as a tourist destination. Overall, the survey technique utilized in this study had demonstrated the ability to assess TDI in a holistic manner especially for a less known destination.

This study has also investigated the effects of travel motivations (general and religious) on destination image formation. The findings revealed that travel motivations significantly affect the cognitive and affective images in a positive direction. Although the influence of travel motivations on affective image has been examined in past studies (e.g. Baloglu \& McCleary, 1999; Beerli \& Martin, 2004a; San Martin \& Rodríguez del Bosque, 2008), the effect on cognitive images was never investigated. The findings of this study have given substantial evidences to establish the relationship between travel motivations and cognitive image. Findings also revealed that the 'Relax' dimension of travel motivations has the greatest direct effect on affective image and all the factors of cognitive images except 'Islamic attractions' (COG 2). This means the desire for relaxation is the dominant factor that would influence the Malaysian Muslims' perception of Taiwan as a tourist destination. On the other hand, the religious dimension of travel motivations did not seems to have much influence since its effect on affective image was not significant. Therefore, the respondents' main reason for traveling to Taiwan is for leisure purpose rather than religious call. Similarly, Din (1989) has also observed that the religious factor does not seems to influence the Muslims' choice of holiday destination. Nevertheless, the religious practices (e.g. halal dietary preference) that are required of the Muslim tourists should not be ignored. Therefore, in order to project a favorable image of Taiwan, the DMO should give more weight on the element of relaxation when promoting the destination to the Muslim 
tourists from Malaysia; at the same time, giving assurance of the availability of halal foods and prayer facilities.

Although this study has successfully measured the image of Taiwan held by the Muslim tourists, and examined the effect of travel motivations on destination image, it was nevertheless not without flaw. Upon examination of the research method, we found certain weaknesses relating to the measurement of travel motivations. Exploratory factor analysis of travel motivations revealed some shortcomings, especially a few items did not load on the intended factors (e.g. social, prestige, excitement, and enjoying nature). In some cases, the respondents might have understood the meaning of the questions differently, and it is possible that cultural difference is the contributing factor. For example, 'Going to places my friends want to go' might be perceived as to participate in the interest of his/her friends, for the sake of social bonding rather than prestige. Therefore, there is a need to formulate questions within the context of the subject's culture, which pose a challenge in cross-cultural study.

In terms of generalization of the findings, it should be cautioned against treating the findings of this study as universal for the Muslims worldwide, since the subject of this study only covered the Muslim tourists in Malaysia. The cultures and travel behaviors among Malaysian Muslims and the Muslim from other regions, such as the Middle East, may still differ in some way although they share the same faith. Therefore, the findings of this study could only be used as a reference for future study, and still require validation before generalizing the findings to the Muslims population worldwide.

\section{Conclusion}

Based on the findings of this study, the Muslim tourists from Malaysia generally have a positive image of Taiwan, however, this image is fuzzy. The availability of halal foods also received substantial attention when the respondents described their impression of Taiwan. This study also investigated the effect of travel motivations on destination image formation by adding a new dimension - the 'Religious' factor. The results confirmed the findings of previous studies that travel motivations have a direct effect on affective image - a crucial component of destination image. The results also revealed that for Malaysian Muslim tourists, relaxation is the key motivation factor that has the greatest impact on image evaluations, contrary to our assumption that religious factor would play an important role in their image evaluations. Thus, religious factor did not seems to affect the Muslim tourists in the evaluations of destination image except concerning religious practices which they must observe, particularly, halal dietary proscriptions.

\section{References}

Ahmed, Z. U. (1991). The influence of the components of a state's tourist image on product positioning strategy. Tourism Management, 12(4), 331-340.

Al-Hamarneh, A., \& Steiner, C. (2004). Islamic tourism: Rethinking the strategies of tourism development in the Arab world after September 11, 2001. Comparative Studies of South Asia, Africa and the Middle East, 24(1), 175.

Alghamdi, A. (2007). Explicit and implicit motivation towards outbound tourism: A study of Saudi tourists (Unpublished $\mathrm{PhD}$ thesis). The University of Glasgow, Scotland.

Baloglu, S. (2001). Image variations of Turkey by familiarity index: informational and experiential dimensions. Tourism Management, 22(2), 127-133.

Baloglu, S., \& Brinberg, D. (1997). Affective images of tourism destinations. Journal of Travel research, 35, 11-15.

Baloglu, S., \& McCleary, K. W. (1999). A model of destination image formation. Annals of tourism research, 26(4), 868-897.

Baud-Bovy, M., \& Lawson, F. (1977). Tourism and Recreation Development. Oxford: Architectural Press. 
Beerli, A., \& Martin, J. (2004a). Factors influencing destination image. Annals of tourism research, 31(3), 657-681.

Beerli, A., \& Martin, J. (2004b). Tourists' characteristics and the perceived image of tourist destinations: A quantitative analysis - a case study of Lanzarote, Spain. Tourism Management, 25(5), 623636.

Bieger, T., \& Laesser, C. (2004). Information sources for travel decisions: Toward a source process model. Journal of Travel Research, 42(4), 357-371.

Boulding, K. (1956). The image: Knowledge in life and society: University of Michigan Press.

Chen, C. F., \& Tsai, D. C. (2007). How destination image and evaluative factors affect behavioral intentions? Tourism Management, 28(4), 1115-1122.

Chen, J. S. (2001). A case study of Korean outbound travelers' destination images by using correspondence analysis. Tourism Management, 22(4), 345-350.

Crompton, J. L. (1979a). An assessment of the image of Mexico as a vacation destination and the influence of geographical location upon that image. Journal of Travel research, 17(4), 18.

Crompton, J. L. (1979b). Motivations for pleasure vacation. Annals of Tourism Research, 6(4), 408-424.

Crompton, J. L., \& Stacey, L. M. (1997). Motives of visitors attending festival events. Annals of tourism research, 24(2), 425439.

Dann, G. (1996). Tourists' images of a destination-an alternative analysis. Journal of Travel \& Tourism Marketing, 5(1), 41-55.

Din, K. (1989). Islam and tourism: Patterns, issues and options. Annals of tourism research, 16(4), 542-563.

Echtner, C. M., \& Ritchie, B. (2003). The meaning and measurement of destination image. Journal of Tourism Studies, 14(1), 37-48.

Fishbein, M. (1967). Attitudes and the prediction of behavior. In M. Fishbein
(Ed.), Readings in attitude theory and measurement. New York: Wiley.

Gallarza, M. G., Saura, I. G., \& García, H. C. (2002). Destination image: Towards

a Conceptual Framework. Annals of tourism research, 29(1), 56-78.

Gartner, W. C. (1993). Image formation process. Journal of Travel \& Tourism Marketing, 2(2/3), 191-215.

Gunn, C. (1972). Vacationscape: Designing tourist regions. Austin, TX: University of Texas Press.

Hair,J.F., Black, W.C., Babin, B. J.,Anderson, R. E., \& Tatham, R. L. (2006). Multivariate data analysis (6th ed.). Upper Saddle River, N.J.: Prentice Hall.

Hunt, J. D. (1975). Image as a factor in tourism development. Journal of Travel research, 13(3), 1-7.

Iso-Ahola, S. E. (1982). Toward a social psychological theory of tourism motivation: A rejoinder. Annals of tourism research, 9(2), 256-262.

Jenkins, O. H. (1999). Understanding and measuring tourist destination images. International Journal of Tourism Research, 1, 1-15.

Kim, H., \& Richardson, S. L. (2003). Motion picture impacts on destination images. Annals of tourism research, 30(1), 216237.

Lin, C. H., Morais, D. B., Kerstetter, D. L., \& Hou, J. S. (2007). Examining the role of cognitive and affective image in predicting choice across natural, developed, and theme-park destinations. Journal of Travel Research, 46(2), 183194.

Neuman, W. L. (2000). Social research methods: Quantitative and qualitative methods (4th ed.). Needham Heights, MA: Allyn $\&$ Bacon.

Parsons, T., \& Shils, E. (2001). Toward a general theory of action: Theoretical foundations for the social sciences. New Brunswick, NJ: Transaction Publishers.

Pew Research Center (2012). Global Religious Landscape. Retrieved from http:// pewresearch.org 
Phelps, A. (1986). Holiday destination imagethe problem of assessment: an example developed in Menorca. Tourism Management, 7(3), 168-180.

Pike, S. (2004). Destination Image. In S. Pike (Ed.), Destination Marketing Organisations (pp. 93-110). Oxford: Elsevier.

Qu, H., Kim, L. H., \& Im, H. H. (2011). A model of destination branding: Integrating the concepts of the branding and destination image. Tourism Management, 32(3), 465476.

Reynolds, W. H. (1965). The role of the consumer in image building. California Management Review, Spring, 69-76.

San Martin, H., \& Rodríguez del Bosque, I. A. (2008). Exploring the cognitive-affective nature of destination image and the role of psychological factors in its formation. Tourism Management, 29(2), 263-277.

Scott, N., \& Jafari, J. (Eds.). (2010). Tourism in the Muslim world. Bingley, UK: Emerald.

Scott, W. (1965). Psychological and social correlates of international images. International behavior: A social- psychological analysis (pp. 70-103). New York: Holt, Rinehart and Winston.

Stepchenkova, S., \& Morrison, A. M. (2008). Russia's destination image among American pleasure travelers: Revisiting Echtner and Ritchie. Tourism Management, 29(3), 548-560.

Timothy, D. J., \& Iverson, T. (2006). Tourism and Islam: Considerations of culture and duty. In D. J. Timothy \& D. H. Olsen (Eds.), Tourism, Religion and Spiritual Journeys (pp. 186-205). London, UK: Routledge.

Vaske, J. J. (2008). Survey research and analysis: Applications in parks, recreation and human dimensions. State College, Pannsyvania: Venture Publishing.

Yoon, Y., \& Uysal, M. (2005). An examination of the effects of motivation and satisfaction on destination loyalty: A structural model. Tourism Management, 26(1), 45-56.

Young, M. (1999). The relationship between tourist motivations and the interpretation of place meanings. Tourism Geographies, 1(4), 387-405. 